\title{
Formation of biofilm by Listeria monocytogenes ATCC 19112 at different incubation temperatures and concentrations of sodium chloride
}

\author{
H.Y. Lee ${ }^{1,2}$, L.C. Chai ${ }^{3}$, C.F. Pui ${ }^{1}$, S.Mustafa ${ }^{2}$, Y.K. Cheah ${ }^{4}$, \\ M. Nishibuchi ${ }^{5}$, S. Radu ${ }^{1}$ \\ ${ }^{1}$ Centre of Excellence for Food Safety Research, Faculty of Food Science and Technology, \\ Universiti Putra Malaysia, Serdang, Selangor Darul Ehsan, Malaysia. \\ ${ }^{2}$ Department of Molecular and Cellular Biology, Faculty of Biotechnology and Biomolecular Science, \\ Universiti Putra Malaysia, Serdang, Selangor Darul Ehsan. \\ ${ }^{3}$ Department of Microbiology, Faculty of Science, Universiti Malaya, Kuala Lumpur, \\ Wilayah Persekutuan, Malaysia. \\ ${ }^{4}$ Department of Biomedical Sciences, Faculty of Medicine and Health Sciences, \\ Universiti Putra Malaysia, Serdang, Selangor Darul Ehsan, Malaysia. \\ ${ }^{5}$ Center for Southeast Asian Studies, Kyoto University, Yoshida Sakyo-ku, Kyoto, Japan.
}

Submitted: December 29, 2010; Approved: September 30, 2012.

\begin{abstract}
Biofilm formation can lead to various consequences in the food processing line such as contamination and equipment breakdowns. Since formation of biofilm can occur in various conditions; this study was carried out using L. monocytogenes ATCC 19112 and its biofilm formation ability tested under various concentrations of sodium chloride and temperatures. Cultures of L. monocytogenes ATCC 19112 were placed in 96-well microtitre plate containing concentration of sodium chloride from $1-10 \%(\mathrm{w} / \mathrm{v})$ and incubated at different temperature of $4{ }^{\circ} \mathrm{C}, 30^{\circ} \mathrm{C}$ and $45{ }^{\circ} \mathrm{C}$ for up to $60 \mathrm{~h}$. Absorbance reading of crystal violet staining showed the density of biofilm formed in the 96 -well microtitre plates was significantly higher when incubated in $4{ }^{\circ} \mathrm{C}$. The formation of biofilm also occurs at a faster rate at $4{ }^{\circ} \mathrm{C}$ and higher optical density (OD $570 \mathrm{~nm}$ ) was observed at $45^{\circ} \mathrm{C}$. This shows that storage under formation of biofilm that may lead to a higher contamination along the processing line in the food industry. Formation of biofilm was found to be more dependent on temperature compared to sodium chloride stress.
\end{abstract}

Key words: Listeria monocytogenes, biofilm, sodium chloride, temperature, microtiter plate.

\section{Introduction}

L. monocytogenes is an aerobic and facultative anaerobic gram positive bacillus that can be found in the environment and food processing facilities. It is one of the major foodborne pathogens that has affected the food industries due to contamination of equipments that lead to cross contamination on food products (Carpentier and Chassaing, 2004; Chi and Zhu, 2009). Contamination on surfaces in the processing environment can be attributed to attachment of pathogenic bacteria. Consequently, attachment of pathogenic microbes leads to biofilm formation. Biofilm is de- fined as an assemblage of surface-associated cells that are enclosed in hydrated extracellular polymeric substances that may contain one or more than one community of microbes (Sauer et al., 2007). Biofilm formation by $L$. monocytogenes contributed to the major persistence characteristic to physical and chemical stress because biofilm not only functions as a protective layer for microbes from the external hostile environment but also as a trap for nutrients (Poulsen, 1999). Accumulation of biofilm layers causes many problems in the industries, for example, microbial contamination in the equipment (Matilla-Sandholm and Wirtanen, 1992) and clogging up of pipes. In addition

Send correspondence to H.Y. Lee. Centre of Excellence for Food Safety Research, Department of Food Science, Faculty of Food Science and Technology, Universiti Putra Malaysia, 43400 Serdang, Selangor Darul Ehsan, Malaysia. E-mail: leehaiyen@gmail.com. 
to the problem, the detachment and dispersal of biofilms due to the increased biomass of biofilm will spread and colonize new niches and it represents a potential harm on food safety aspect.

Association of biofilm and L. monocytogenes in foods have been reported in several studies previously, for example, contamination of $L$. monocytogenes biofilm in beef surface (Dickson, 1990) and smear cheese wooden shelves (Guillier et al., 2008), dairy processing plants particularly on the brines and equipments (Alessandria et al., 2010). It is frequently communicated in literatures that food contamination by L. monocytogenes occurs post processing instead of survival of processing stages (McLauchlin, 1987). Formation of biofilm occurs when microcolony formed on the surface adheres with a conditioning film that traps the surrounding fluid and nutrients. The formation of microcolony will become an irreversible process due to the growth of bacteria and production of extracellular polymer substances (EPS) that aids the anchorage of cells and stabilizes the external environment stress on the cells (Characklis and Marshall, 1990). Major issues caused by biofilms are the inability of commercial cleaners or bleach to remove the biofilms contaminating the equipments; therefore, preventive measures of controlling biofilm lies in the frequency of cleaning the equipments.

Few key factors of biofilm formation by $L$. monocytogenes have been recognized such as conditions of surface for attachment, organic or inorganic matter, levels of nutrients available, $\mathrm{pH}$, temperature, adhesion strength, strain types, monoculture or mixed cultures, as well as other environmental stresses (Houdt and Michiels, 2010). It has been established that availability of nutrients can affect the density of biofilm formation. Contaminated foods through contact surfaces such as stainless steel (De Oleiveira et al., 2010) with biofilm will allow growth and maturation of the biofilm structure and spread of biofilm in the food industry. Particularly in processing and storage, long term storage at various temperatures plays a critical role in determining the density of biofilm formation in the food products. The consequences of Listeria contaminated foods may not only present detrimental health effect but also implies economic losses as a result of biofouling, a term describing the biofilm attaching to a surface that will spoil the food products and equipments.

The biofilm formation of $L$. monocytogenes may also differ between serotypes (Harvey et al., 2007) which contribute to the spread of contamination of $L$. monocytogenes in foods. As serotype 1/2c has been commonly associated to contamination of foods, understanding the ability of the microorganism to form biofilm under adverse conditions may extend the knowledge for its appropriate control.

The objective of this study was to evaluate the formation of biofilm by L. monocytogenes ATCC 19112 (serotype $1 / 2 c$ ) under the different incubation temperatures and concentrations of $\mathrm{NaCl}$.

\section{Materials and Methods}

\section{Bacteria strain}

L. monocytogenes ATCC 19112 (serogroup 1/2c) was grown overnight on tryptic soy agar (with $0.6 \%$ yeast extract) at $37^{\circ} \mathrm{C}$. Colonies were isolated using sterile swabs and transferred into tubes containing $15 \mathrm{~mL}$ of saline and further adjusted to the turbidity of McFarland standard No. 5 which corresponds to $10^{8} \mathrm{CFU} / \mathrm{mL}$. Serial dilutions were carried out to ensure that the final concentration of cells in each well was standardized to $10^{6} \mathrm{CFU} / \mathrm{mL}$.

\section{Microtiter plate assay}

$100 \mu \mathrm{L}$ volume of inoculums were dispensed into 96-well containing variable percentage of sodium chloride (final concentration in each well: 1, 2, 3, 4, 5, 6, 7, 8, 9, 10\% w/v) with each well containing a final concentration of $10^{6} \mathrm{CFU} / \mathrm{mL}$. Every experiment, performed in duplicate, comprised of at least five individual replicates. Plates were each incubated in three different temperatures of $4{ }^{\circ} \mathrm{C}$, $30^{\circ} \mathrm{C}$ and $45^{\circ} \mathrm{C}$ for $60 \mathrm{~h}$. Readings of the plates were taken with $12 \mathrm{~h}$ intervals. Appropriate controls of uninoculated growth (negative control) and normal saline $(0.85 \% \mathrm{NaCl})$ were included in the tests.

\section{Crystal violet staining}

The crystal violet procedure was slightly modified from Silagyi et al. (2007) with the following details. Firstly, the microplates were lightly rinsed with deionized water to remove the suspended cells in the saline. Then, $200 \mu \mathrm{L}$ of $0.25 \%(\mathrm{w} / \mathrm{v})$ crystal violet (filter sterilized) were added into each well using a multi-channel micropipette and left at $25^{\circ} \mathrm{C}$ for $30 \mathrm{~min}$ in the laminar airflow. The microplates were then rinsed three times and allowed to dry in sterile laminar airflow. Finally, the crystal violet stains in the biofilm were solubilized by adding $200 \mu \mathrm{L}$ of absolute ethanol for $30 \mathrm{~min}$ and proceed for microplate spectrophotometer reading (BIORAD Spectrophotometer 170-6930, Berkeley, U.S.A) at $570 \mathrm{~nm}$. In order to correct the background staining, the mean optical density of the negative control was used to subtract the optical density of the biofilm formed in each inoculated wells.

\section{Statistics of results}

Readings from the 96-well plates were obtained as absorbance measurements after adjustment of the blank negative control. Data presented shows the mean data generated from the replicates and from all experiments using ANOVA analysis in SPSS Statistics 17.0.

\section{Results and Discussion}

Based on the statistical analysis, there was an indication of statistical significance being observed for formation of biofilm at temperatures such as $4{ }^{\circ} \mathrm{C}$ and $45^{\circ} \mathrm{C}$ at differ- 
ent intervals and sodium chloride concentrations (Figure 1). At $4{ }^{\circ} \mathrm{C}$, analysis of variances (ANOVA) showed there is a statistical significance between the absorbance of biofilm being affected by sodium chloride concentration $(\mathrm{df}=10, \mathrm{~F}=2.848, \mathrm{p}=0.002)$ as well as hour of incubation $(\mathrm{df}=4, \mathrm{~F}=63.057, \mathrm{p}<0.005)$. No significant correlations were found in between readings of biofilm formation and sodium chloride concentration (Pearson correlation $=$ $-0.017, \mathrm{p}=0.75$ ) and hour (Pearson correlation $=-0.025$, $\mathrm{p}=0.643)$. For the temperature of $30^{\circ} \mathrm{C}$, there were no significant differences on the effect of sodium chloride on absorbance $(\mathrm{df}=10, \mathrm{~F}=0.979, \mathrm{p}=0.461)$ but there was a significant difference on the effect of hour on biofilm formation $(\mathrm{df}=4, \mathrm{~F}=21.56, \mathrm{p}<0.05)$. There were no statistical significant correlations found between incubation time $($ Pearson $=0.081)$ and sodium chloride $($ Pearson $=-0.026)$ with absorbance reading. As for results at $45^{\circ} \mathrm{C}$, incubation hour showed statistical significance on the formation of biofilm $(\mathrm{df}=4, \mathrm{~F}=14.068, \mathrm{p}<0.05)$ while no statistical significance was found when affected by sodium chloride concentration $(\mathrm{df}=10, \mathrm{~F}=1.55, \mathrm{p}<0.12)$. Correlation of absorbance reading was found to be significant for both incubation time $($ Pearson $=0.119)$ and sodium chloride concentration $($ Pearson $=0.124)$.

In previous studies, numerous reports emphasized on the study of a single strain only, for example, $L$. monocytogenes Scott A (serotype $4 \mathrm{~b}$ ) and limited studies have explored the biofilm formation potential of the other L. monocytogenes serotypes. Formation of biofilm by serogroup $1 / 2 \mathrm{c}$ has been disputed in other studies such as Kalmokof et al. (2001) that L. monocytogenes only adheres to surfaces and does not form biofilm while Borucki et al. (2003) reported that formation of biofilm by serogroup 1/2c is higher when compared to other strains such as serotype $4 \mathrm{~b}$. Findings from this study showed that $L$. monocytogenes ATCC 19112 is a microorganism able to form biofilm with

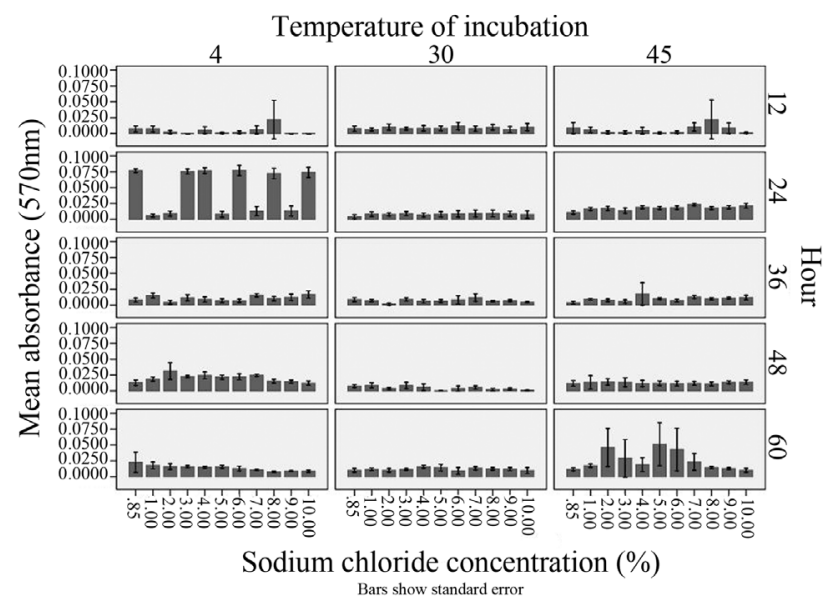

Figure 1 - Formation of biofilm, assessed by optical density readings obtained at wavelength of $570 \mathrm{~nm}$ (OD $570 \mathrm{~nm}$ ) by Listeria monocytogenes ATCC 1911 at different concentrations of sodium chloride (1 to $10 \%, \mathrm{w} / \mathrm{v}$ ) and incubation temperatures of $4{ }^{\circ} \mathrm{C}, 30^{\circ} \mathrm{C}$ and $45^{\circ} \mathrm{C}$. minimal nutrient requirements, for example, in presence of only $\mathrm{NaCl}$. In addition to that, Stephanovic et al. (2004) and Harvey et al. (2007) concluded that the reduced concentration of TSB in their studies led to reduced planktonic and biofilm being observed in their studies. Therefore, in the present study of utilizing various concentrations of $\mathrm{NaCl}$ only, general readings of optical density were expected to be lower than the previous studies.

Detection of biofilm formation was measured at a lower scale compared to similar studies by Pan et al. (2010). The main difference between the present study and Pan et al. (2010) was that, in the last one, the colonies were incubated with tryptic soy broth as nutrient and $\mathrm{NaCl}$ as additional nutrients. The formation of biofilm was enhanced as a synergistic effect on the combination of glucose, $\mathrm{NaCl}$ and TSB (Pan et al., 2010). In this study, emphasis was placed on the cellular stress by $\mathrm{NaCl}$ instead of $\mathrm{NaCl}$ as additional nutrient to the cells. Nonetheless, it has been noted that addition of $\mathrm{NaCl}$ to TSB enhances the adherence of the cells and increases the invasiveness of the strains (Jensen et al., 2007). According Norwood and Gilmour (2001), the adherence capability of L. monocytogenes FM876 (serotype $1 / 2 \mathrm{c}$ ) was found to be greater than L. monocytogenes Scott $\mathrm{A}$, as seen at $4{ }^{\circ} \mathrm{C}, 18{ }^{\circ} \mathrm{C}$ and $30^{\circ} \mathrm{C}$. Formation of biofilm by $L$. monocytogenes can be affected depending on the existence as monoculture or multispecies in biofilm matrix, such as Staphylococcus biofilm may produce extracellular polysaccharides that may prevent the adhesion to stainless steel surfaces (Leriche and Carpentier, 2000). Changes in the cell surface can also be caused by the changes in regulation of virulence and environmental genes as a result of temperature changes (Leimeister-Wachter $e t$ al., 1992; Liu et al., 2002) and subsequently affects the attachments of cells such as properties of surfaces being hydrophobic or hydrophilic.

In previous phylogenetic studies, L. monocytogenes has been divided into two phylogenetic divisions, as follows: Division I consisting serotype $4 \mathrm{~b}$ and $1 / 2 \mathrm{~b}$ while Division II consist of serotype 1/2a and 1/2c (Bibb et al., 1990; Borucki et al., 2003; Carpentier and Chassaing, 2004). Pan et al. (2010) compared serotype of $1 / 2$ a (Division II) and serotype $4 \mathrm{~b}$ (Division I) and found that serotype $1 / 2 \mathrm{a}$ was better adapted to survival and growth in adverse conditions. A study performed by Folsom et al. (2006) also compared the biofilm formation of these two serotypes under availability of different nutrients and reported that growth of $1 / 2$ a strains produced more biofilm in diluted tryptic soy broth than serotype $4 \mathrm{~b}$. Lower nutrient levels contributed to the response on biofilm formation by serotype $1 / 2$ a suggesting that different regulatory mechanism was involved in the biofilm phenotype. However, those two authors observed no association between genetic subtype and amount of biofilm accumulated and Borucki et al. (2003) reported that Division II (serotype 1/2a and 1/2c) has an increased biofilm formation ability. This suggests 


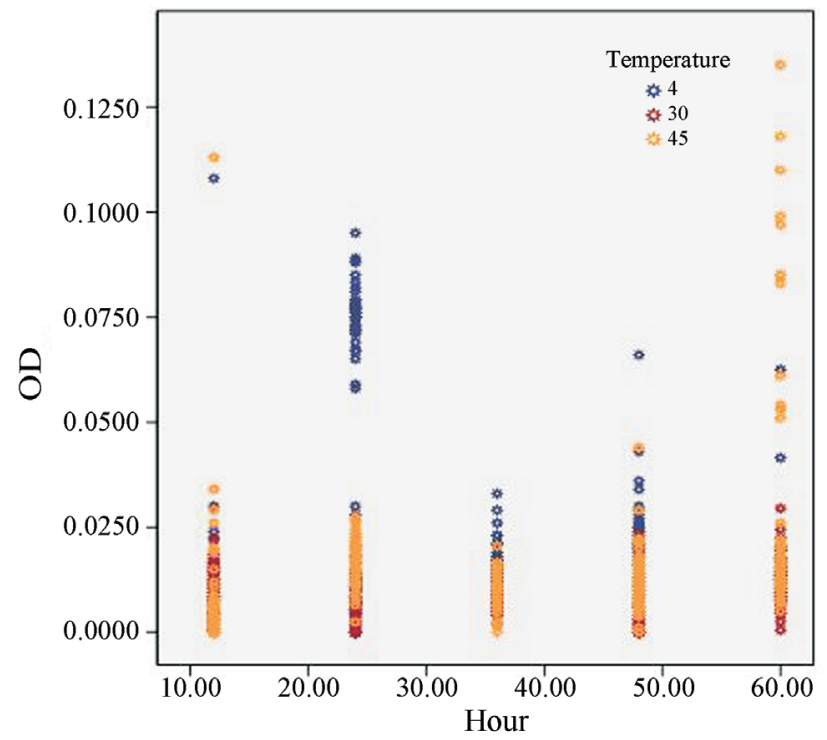

Figure 2 - Overall results obtained for biofilm formation of Listeria monocytogenes ATCC 19112 incubated at $4{ }^{\circ} \mathrm{C}, 30^{\circ} \mathrm{C}$ and $45^{\circ} \mathrm{C}$ determined by optical density readings (OD $570 \mathrm{~nm}$ )

that Division II may have better adaptation to adverse conditions and contributes to the higher prevalence of isolates belonging to serotype $1 / 2$ in food processing plants. Furthermore, according to Harvey et al. (2007) that irrespective of the source of isolates, the ESE type II (serotype $1 / 2 \mathrm{c}$ ) has greater biofilm formation compared to the others.

This study was conducted to extend the knowledge of other $L$. monocytogenes strains that are more frequently found in foods (Division II) and the ability to form biofilm in different conditions. According to our findings, we can conclude that formation of biofilm by L. monocytogenes ATCC 19112; i) can occur faster with a higher optical reading $(570 \mathrm{~nm})$ in $4^{\circ} \mathrm{C}$ (Figure 2); ii) has a wide range of $\mathrm{NaCl}$ tolerance (up to $10 \% \mathrm{w} / \mathrm{v}$ ) which induces cellular stresses and has a positive influence on the biofilm forming ability; iii) will increase with the time of incubation at higher temperature of $45^{\circ} \mathrm{C}$. These factors may present critical points in the control of the persistence and contamination of $L$. monocytogenes along the food processing line.

\section{Acknowledgments}

This research is funded by Ministry of Health Malaysia and supported in-part by Grant-in Aid for Scientific Research (KAKENHI 191010) from Japan Society for the Promotion of Sciences.

\section{References}

Alessandria V, Rantsiou K, Dolci P, Cocolin L (2010) Molecular methods to assess Listeria monocytogenes route of contamination in a dairy processing plant. Int $\mathrm{J}$ Food Microbiol 141:S156-S162.

Bibb WF, Gellin BG, Weaver R, Schwartz B, Plikaytis BD, Reeves MW, Pinner RW, Broome CV (1990) Analysis of clicnical and food-borne isolates of Listeira monocytogenes in the United States by multilocus enzyme electrophoresis and application of the method to epidemiologic investigations. App Env Microbiol 56:2133-3141.

Borucki MK, Kurg MJ, Muruoka WT, Call DR (2003) Discrimination among Listeria monocytogenes isolates using mixed genome DNA microarray. Vet Microbiol 92:351-362.

Call DR, Borucki MK, Besser TE (2003) Mixed-genome microarray reveals multiple serotype and lineage-specific differences among strains of Listeria monocytogenes. J Clin Microbiol 41:632-639.

Carpentier B, Chassaing D (2004) Interactions in biofilms between Listeria monocytogenes and resident microorganisms from food industry premises. Int J Food Microbiol 97:111122.

Characklis WG, Marshall KC (1990) Biofilm processes. In: Characklis WG, Marshal KC (eds). Biofilms. John Wiley, New York, pp 195-231.

De Oleivera MMM, Brugnera DF, Alves E, Piccoli RH (2010) Biofilm formation by Listeria monocytogenes on stainless steel surface and biotransfer potential. Braz J Microbiol 41:97-106.

Dickson JS (1990) Survival and growth of Listeria monocytogenes on beef tissue surfaces as affected by simulated processing conditions. J Food Safety 10:165-174.

Folsom JP, Siragusa GR, Frank JF (2006) Formation of biofilm at different nutrient levels by various genotypes of Listeria monocytogenes. J Food Prot 69:826-834.

Guillier L, Stahl V, Hezard B, Notz E, Briandet R (2008) Modeling the competitive growth between Listeria monocytogenes and biofilm microflora of smear cheese wooden shelves. Int J Food Microbiol 128:51-57.

Harvey J, Keenan KP, Gilmour A (2007) Assessing biofilm formation by Listeria monocytogenes sstrains. Food Microbiol 24:380-392.

Houdt RV, Michiels CW (2010) Biofilm formation and food industry, a focus on the bacterial outer surface. J Appl Microbiol 109:1117-1131.

Jensen A, Larsen M, Ingmer H, Vogel BF, Gram L (2007) Sodium chloride enhances adherence and aggregation and strain variation influences invasiveness of Listeria monocytogenes strains. J Food Prot 70:592-599.

Kalmokoff ML, Austin JW, Wan XD, Sanders G, Banergee S, Farber JM (2001) Adsorption, attachment and biofilm formation among isolates of $L$. monocytogenes using model conditions. J Appl Microbiol 91:725-734.

Leimeister-Wachter M, Domann E, Chakraborty T (1992) The expression of virulence genes in Listeria monocytogenes is thermoregulated. J Bacteriol 174:947-952.

Leriche V, Carpentier B (2000) Limitation of adhesion and growth of Listeria monocytogenes on stainless steel surfaces by Staphylococcus sciuri biofilms. J Appl Microbiol 88:594-605.

Liu S, Graham JE, Bigelow L, Morse PDII, Wilkinson BJ (2002) Identification of Listeria monocytogenes genes expressed in response to growth at low temperature. Appl Env Microbiol 68:1697-1705.

Mattila-Sandholm T, Wirtanen G (1992) Biofilm formation in the industry: A Review. Food Rev Int 8:573-603. 
McLauchlin J (1987) Listeria monocytogenes, recent advances in taxonomy and epidemiology of listeriosis in humans. J Appl Bacteriol 63:1-11.

Norwood DE, Gilmour A (2001) The differential adherence capabilities of two Listeria monocytogenes strains in monoculture and multispecies biofilms as a function of temperature. Lett Appl Microbiol 33:320-324.

Pan Y, Breidt Jr F, Gorski L (2010) Sygergistic effects of sodium chloride, glucose and temperature on biofilm formation by Listeria monocytogenes serotype $1 / 2 \mathrm{a}$ and $4 \mathrm{~b}$ strains. Appl Environ Microbiol 76:1433-1441.

Poulsen LV (1999) Microbial biofilm in food processing. Lebensm Wiss Technol 32:321-326.
Sauer K, Rickard AH, Davies DG (2007) Biofilms and biocomplexicity. Microbes 2:347-353.

Shi X, Zhu X (2009). Biofilm formation and food safety in food industries. Trends Food Sci Tech 20:407-413.

Silagyi K, Kim SH, Lo YM, Wei C (2007) Production of biofilm and quorum sensing by Escherichia coli $\mathrm{O} 157: \mathrm{H} 7$ and its transfer from contact surfaces to meat, poultry, ready-to-eat deli, and produce products. Food Microbiol 26:514-519.

Stephanovic S, Cirkovic I, Ranin L, Svabic-Vlahovic M (2004) Biofilm formation by Salmonella spp. and Listeria monocytognes on plastic surfaces. Lett Appl Microbiol $38: 428-432$

All the content of the journal, except where otherwise noted, is licensed under a Creative Commons License CC BY-NC. 